\title{
Application of the multispectral images analysis in the near infrared spectrum to evaluate dried murtilla (Ugni molinae Turcz) fruits obtained by different drying methods
}

\author{
by C. San Martín*, E. Scheuermann ${ }^{* *}$ and R. Andrade* \\ * Information Processing Laboratory IPL, Universidad de La Frontera, Casilla 54-D, Temuco, Chile, \\ ${ }^{*}$ Center for Optics and Photonics CEFOP, Universidad de Concepción, Concepción, Chile \\ (cesarsanmartin@ufro.cl), (r.andrade02@ufromail.cl) \\ **Departamento de Ingeniería Química, Universidad de La Frontera, Casilla 54-D, Temuco, Chile \\ (ericks@ufro.cl)
}

\begin{abstract}
This work presents a development of an index which represents the homogeneity of the water's concentration in a berry fruit type called 'Murtilla' which has been dehydrated by different process. The analysis was made by a technique called imaging spectroscopy in reflection mode using near infrared spectrum. This analysis considers the band centered at $1450 \mathrm{~nm}$ of wavelength, because this absorption band represents the water's presence. The proposed homogeneity index depends of the reflected infrared radiation by the murtilla, and was calculated comparing the murtilla's digital value obtained by the multispectral camera.
\end{abstract}

Keywords: NIRS, Murtilla, variability index, radiation spectrum

\section{Introduction}

Through the imaging spectroscopy can made a non-intrusive, non-destructive and free-contact analysis, which does not alter the sample. In this analysis we work with multispectral images, which represent small segments of the wavelength of the infrared radiation reflected by the samples [1]. It was demonstrate that the absorption of infrared radiation in some spectral band represents the principal components of the food, especially water molecules which wavelength characteristic around the $1450 \mathrm{~nm}$ [2].

The native Chilean specie, Ugni molinae Turcz commonly named as "murtilla", "mutilla" or "murta", is a wild perennial shrub growing in the South of Chile. This plant produces a small globoid berry fruit with an equatorial diameter of $0.71-1.31 \mathrm{~cm}$ [3]. This fruit has potential beneficial effects on human health and may be used as a natural preservative in a variety of food products [4]. The fresh fruit has a unique, penetrating aroma; along with its pleasant, sweet flavor, this makes it popular for consumption [5]. Volatile compounds of the murtilla fruit aroma have been determinate of which methyl 2-methyl butanoate, ethyl butanoate, ethyl 2-methyl butanoate, methyl hexanoate, ethyl hexanoate, methylbenzoate, and ethyl benzoate were the major components [6].

The murtilla is an important berry in the exportations, and they must be dehydrated to reduce the cost of his transport and avoid damage due to an excess of water or moisture in the trip [7]. Drying is a popular method used for food preservation and water content influence the food product quality. Common drying methods used in food preservation are air convection, osmotic dehydration, freezing and vacuum microwave drying. The effect on quality fruit is important to decide the better drying method [8].

Recently, it was determinate that the optimal conditions in atmospheric freeze drying by fluidization with dry air (fast freezing with IR and air at $15^{\circ} \mathrm{C}$ for the second drying stage) allowed achieving final moisture contents similar to vacuum freeze drying and similar sensory attributes, in equivalent total drying periods.

The objective of this research was to use an index measure by multispectral images analysis in the near infrared spectrum to determinate uniformity level of the murtilla (Ugni molinae Turcz) fruits dried obtained by three different drying methods.

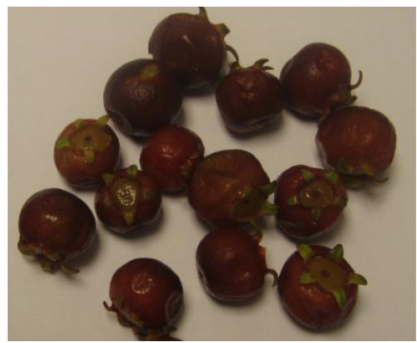

Fig. 1. Murtilla berry. 


\section{Theory}

Infrared radiation (IR) is a kind of electromagnetic radiation which has a higher wavelength range that the visible spectrum. Typically is segmented by three different wavelength ranges in near wavelength Infrared spectrum (NIR or NWIR: between 0.7 and $1.8 \mu \mathrm{m}$ ), middle wavelength infrared spectrum (MWIR: between 1.8 and $8 \mu \mathrm{m}$ ) and the far wavelength (LWIR: from 8 to $100 \mu \mathrm{m}$ ) [9].

Imaging spectroscopy is an analysis of the interaction of the light with material due to the atoms or molecules compositions of the material. This analysis could be applied in any range of the spectrum, either visible or infrared. In this work the imaging spectroscopy is focused in the near infrared spectrum, and it was applied in reflection mode. The images are captured using a multispectral camera, where each pixel represents the intensity of the reflected radiation of the samples captured by the sensors, one per each wavelength of the segmented spectra and is called multispectral images.

This camera contains a focal plane array of detectors (FPA) with the capacity to detect different wavelengths. This FPA is composed by 236 rows, each one with different wavelength detection; these rows have a line of 324 detectors of the same range detection capacity. The procedure of the camera to obtain the image is capturing a real row of the sample, which is detected by all the FPA directed by the camera optic, generating 236 rows at different wavelength of the real row. So, is necessary to move the sample under the camera focus to generate an image, like the movement of a scanner. This movement must be synchronized with the integration time of the camera detectors, to generate a proportional and representative multispectral image. Depending the time used in this step the dimension of the image will be configure, e.g. in this work the time used generate an image of $324 \times 256$ pixels.

As every acquisition devices, the multispectral camera has a higher capacity of detect some wavelength ranges than others. The responsivity curve of the camera detectors is used to compensate differences in detection process, obtained in [10] and shown in figure 2.

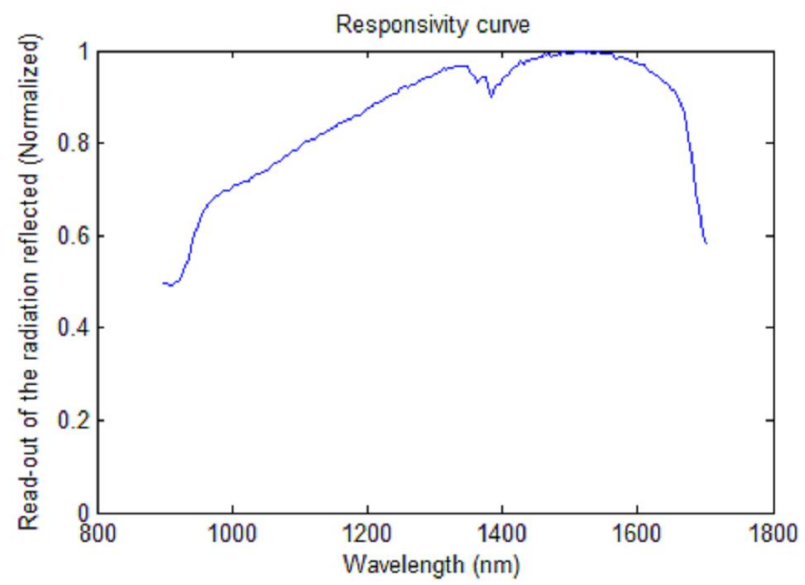

Fig. 2. Responsivity curve for multispectral camera Xenics Xeva.

The principal scope of this work corresponds to the detection of humidity of a sample using the absorption bad of $\mathrm{H}_{2} \mathrm{O}$ components, principally in $1450 \mathrm{~nm}$ wavelength [11,12]. Figure 3 show the overtone of the $\mathrm{O}-\mathrm{H}$ combination appeared.

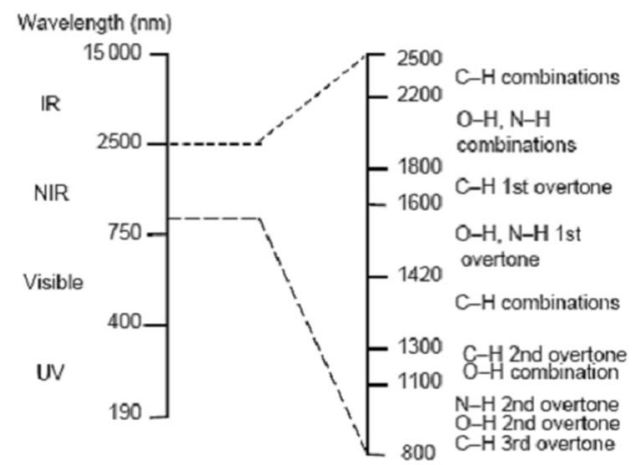

Fig. 3. Principal types of NIR absorption bands and their locations. 
In this paper the standard deviation is used as an index that represents the moisture difference in a group of murtilla berry, in order to know the homogeneity of the applied drying method. The proposed index is calculated in the readout data given by the camera in the form:

$$
\text { Homogeneity index }=\mathrm{S}=\sqrt{\frac{\sum_{\mathrm{i}=1}^{\mathrm{n}}(\mathrm{x}(\mathrm{i})-\overline{\mathrm{x}})^{2}}{\mathrm{n}}},
$$

where $X(i)$ is the readout data for the "i" sample, $\bar{X}$ is the average of the read out and $n$ is the quantity of samples for each class of drying murtilla.

A lower index means that the humidity of his samples is more homogeneous than a higher index, i.e. in the sample set, murtillas dried by a same method presents similar digital value levels from the camera readout.

\section{Experimental setup, materials and methods}

In this work the data set was recorded with the NIR multispectral camera Xenics Xeva (Figure 4), able to detect near infrared radiation into the 0.9 and $1.7 \mu \mathrm{m}$ of wavelength. This camera captures the reflected radiation by dried murtilla fruit samples and generates 236 images of $324 \times 256$ pixels with a resolution of 14 bits per pixel, distributed in detection range with a mean wavelength span about to $3.4 \mathrm{~nm}$. This span list is determinate by the following calibration equation:

$$
\operatorname{Span}(i)=0.00060434 * i^{2} 3.258 * i+876.719,
$$

where $X(i)$ is the digital value for the "i" sample, $\bar{X}$ is the average of the read-out and $n$ is the quantity of samples. A quartz tungsten halogen lamp (figure 5 ) is available too, which is directed to the samples to obtain the reflected radiation by the murtillas, this lamp emit a uniform intensity in the wavelength range and his power is 200 Watts. The sample set consists of 3 murtilla groups, each one with about 10 murtillas classified by the drying methods applied on them, how can be seen in figure 6.

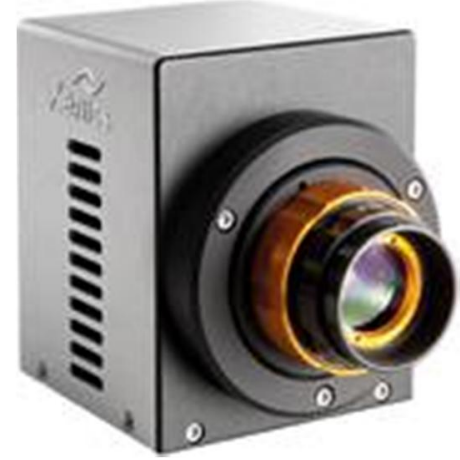

Fig. 4. Multispectral NIR camera Xenics Xeva.

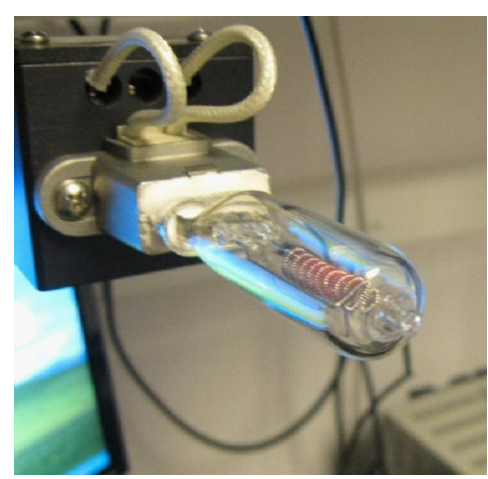

Fig. 5. Tungsten lamp.

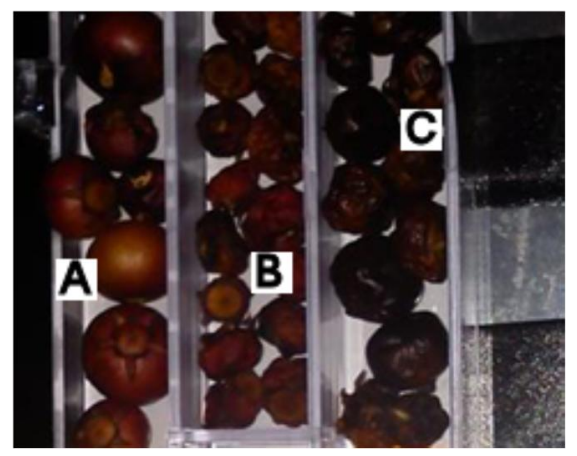

Fig. 6. 'Murtilla' in the experimental setup classified by the dehydration process. (A- Vacuum microwave, $B$ Air convection, C- Osmotic dehydration) 
The experimental setup used for conducting the tests is shown in figure 7 , where the dried murtilla fruits were placed in a separate receptacle depending which drying method was applied on them (Vacuum microwave, air convection and osmotic dehydration in figure 6). The receptacle is moved along the support to obtain the multispectral image; this movement is synchronized with the integration time of the camera to obtain a proportional and representative image of the scene. Before that, the tungsten lamp was configured to 200 Watts.

The recording data of the samples with the multispectral camera begins once the lamp has been turned on and directed towards the sample obtaining the infrared images within the detection range (figure 8), applying by this way the spectroscopy in reflection mode in the near infrared spectrum.

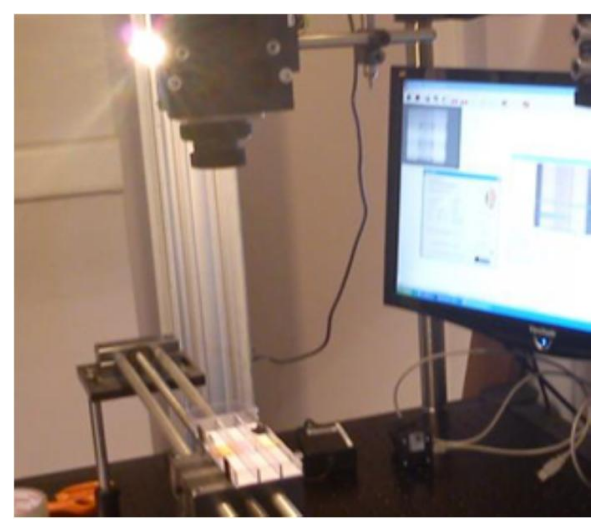

Fig. 7. Experimental setup.

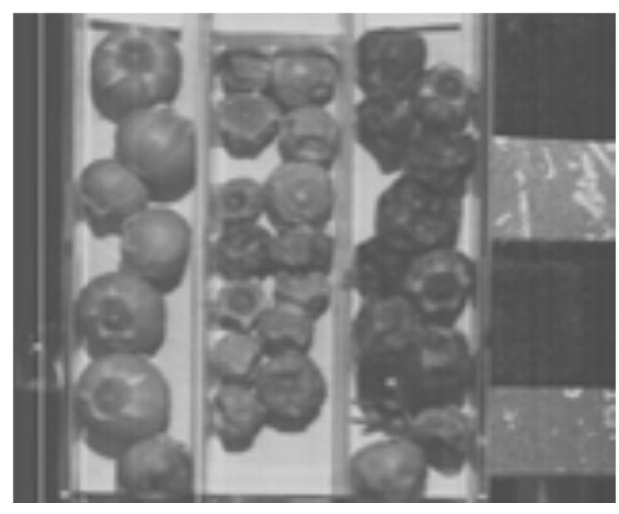

Fig. 8. Image of dried murtilla fruits at $\sim 1450 \mathrm{~nm}$ of wavelength

Once data set is acquired, the digital level that represents the reflected radiation must be extracted from the infrared image, for which applies the following imaging post-processing: five murtillas are selected for each one of the drying method, where for every of the murtillas a 10x10 pixel area is determined to obtain the mean of his digital value, from this, the representative digital level for each murtilla is obtained.

This process is repeated for all spectral images, to obtain the reflected radiation by the murtillas for each one of the wavelength detected by the camera. This data allows generating the spectrum curve for each one of the selected murtilla fruit. From this step, the data set is ready to obtain his homogeneity index for every drying method for any segment of the all wavelength range.

The $10 \times 10$ pixel square area can be seen in figure 9 , where is taken 5 samples area of $10 \times 10$ pixels each one, for the Vacuum Microwave Drying in this example image.

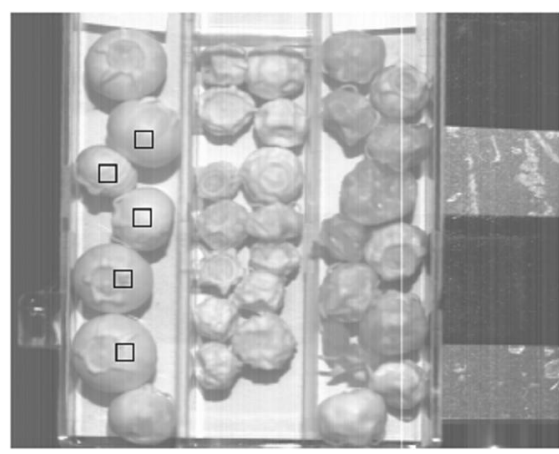

Fig. 9. Example of square samples areas for the vacuum microwave drying method in this case.

With the representative digital level for every murtillas from the sample set, the next step is select the wavelengths that could be affected by the bad absorption of water, that is the $1450 \mathrm{~nm}$ wavelength and around.

The chosen wavelengths was the following: $1437 \mathrm{~nm}, 1441 \mathrm{~nm}, 1444 \mathrm{~nm}, 1448 \mathrm{~nm}, 1451 \mathrm{~nm}, 1454 \mathrm{~nm}$ and $1458 \mathrm{~nm}$, where this value means the center of each segment and the average width is near to $3.4 \mathrm{~nm}$. This selection is used to obtain the homogeneity index only at wavelengths related to presence of water. 
Now, an important step to get an accurately representation of the reality is the compensation with the responsivity curve of the camera, this curve can be seen in the figure 3 .

This curve represents the sensibility to detect different wavelengths of the spectrum. Some wavelengths are detected with more intensity than others.

The way to realize this compensation is applying the Eq. (3).

$$
\mathrm{I}_{\mathrm{f}}(\mathrm{w})=\mathrm{I}(\mathrm{w}) / \mathrm{R}(\mathrm{w})
$$

where $I(w)$ is the spectrum of the murtilla, $R(w)$ is the responsivity curve of the camera, $I_{f}(w)$ is the compensated spectrum of the murtilla and $\mathrm{w}$ is the wavelength.

When this compensation is done, the Eq. (1) is applied over the data to calculate the index for every selected murtilla for each one of the 7 selected wavelengths, obtaining the values for each drying method. Below, an average of the seven bands is calculated and can be appreciated which of the three methods produces a more homogeneous result.

\section{Results and discussion}

With the applied imaging spectroscopy was obtained an interesting set of curves by each murtilla previously selected of the group, these curves represented the expected results and can be seen below.

The figure 10 shows the reflected radiation curves of the five samples of dried murtilla fruit obtained by the three different drying methods. From these curves, is possible to appreciate that the band of the spectrum near the 1,450 nm of wavelength shows a clearly difference in the reflected radiation digital values. These curves were normalized in order to compare them and then are compensated with the responsivity curve of the multispectral camera (figure 2) applying the Eq. (3).

In the figure 11 can be seen the digital values of the murtilla samples for the seven selected wavelengths for each one of drying methods.

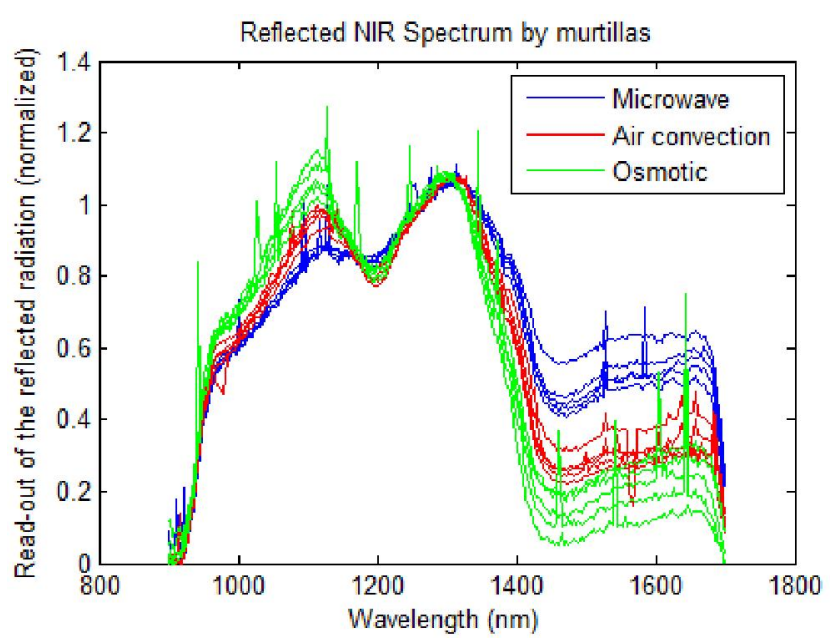

Fig. 10. Reflection Spectrum for samples of dried murtilla fruit obtained by different drying methods.

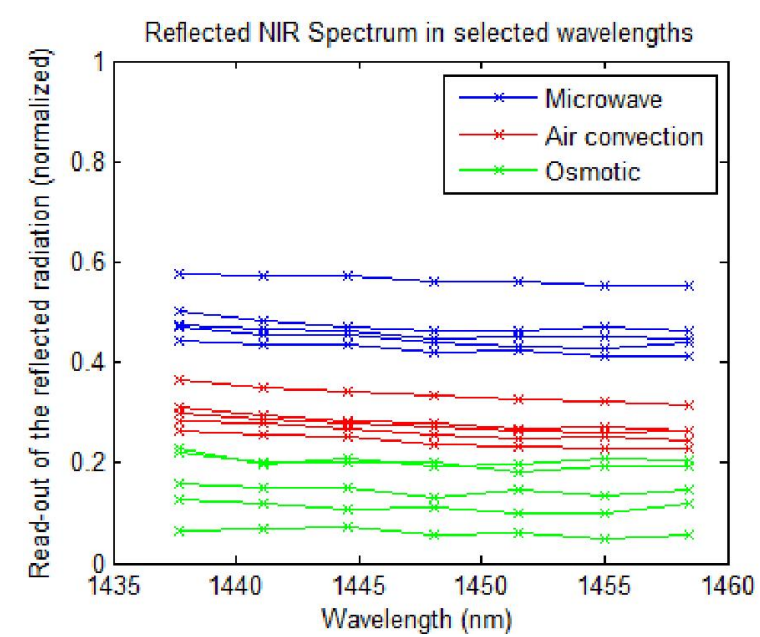

Fig. 11. Reflection digital value for selected wavelengths.

With the representative digital levels calculated for each murtilla at every selected wavelength, the homogeneity index can be obtained. For this, the digital levels of every samples of the group must be operated with the Eq. (1), obtaining the index that represents the variability of the reflected radiation by each one of the murtillas.

At the figure 11, a priori can be seen that the air convection method presents less variation into his samples, but must be analyzed with the homogeneity indexes. These indexes are shown in the table 1, where is listed in columns the three drying methods, and for each one of these are calculated 7 indexes for the proposed wavelengths by his relation with the presence of water.

It can be appreciated that the air convection presents a lowest average homogeneity index than the other 2 drying method. That means that according with this index; the method produces a more homogeneous drying process in the murtilla, generating fruits with similar presence of water in them.

The other methods can be more effectives to dry the fruit that the air convection, but it will be worst at the moment that would be needed to ensure the quality of a dried group of murtilla berries. 
Table 1. Homogeneity index of the dried murtilla fruit obtained by different drying methods.

\begin{tabular}{|c|c|c|c|}
\hline $\begin{array}{c}\text { Wave- } \\
\text { length }\end{array}$ & $\begin{array}{c}\text { Vacuum } \\
\text { microwave }\end{array}$ & $\begin{array}{c}\text { Air } \\
\text { convection }\end{array}$ & $\begin{array}{c}\text { Osmotic } \\
\text { dehydration }\end{array}$ \\
\hline $1437 \mathrm{~nm}$ & 0.045 & 0.0331 & 0.0614 \\
\hline $1441 \mathrm{~nm}$ & 0.047 & 0.0311 & 0.0502 \\
\hline $1444 \mathrm{~nm}$ & 0.047 & 0.0303 & 0.0524 \\
\hline $1448 \mathrm{~nm}$ & 0.049 & 0.0323 & 0.0531 \\
\hline $1451 \mathrm{~nm}$ & 0.049 & 0.0318 & 0.0504 \\
\hline $1454 \mathrm{~nm}$ & 0.048 & 0.0313 & 0.0589 \\
\hline $1458 \mathrm{~nm}$ & 0.048 & 0.0281 & 0.054 \\
\hline Average & 0.048 & $\mathbf{0 . 0 3 1 1}$ & 0.0543 \\
\hline
\end{tabular}

\section{Conclusions}

Infrared imaging spectroscopy gives an excellent non-destructive, non-invasive and free-contact analysis. From this analysis is possible to obtain a significant data set without alter the sample.

Due that is worked over images that contain a lot of usable pixels, is possible to get a lot of information with a few of image captures. This analysis is very simple to realize too. Among other advantages can be highlighted the easily and fastness of this analysis realization.

The proposed homogeneity index gives representative information about moisture content variability of dried murtilla fruit obtained by different drying detected in near of the $1,440 \mathrm{~nm}$. For this sample set the air convection produces a more homogenous dried murtilla fruit among the samples evaluate using the multispectral images analysis.

The more complex step to obtain this index is select an appropriated area of the murtilla to obtain a representative value, thus, the future study to this analysis will be focuses to improvement this selection by an artificial intelligence method.

\section{Acknowledgment}

Authors thanks to Center of Optics and Photonics (CEFOP), at the "Universidad de Concepción", Concepción, Chile, Information Processing Laboratory (IPL), at the "Universidad de La Frontera", in Temuco, Chile and the Optoelectronic Laboratory, at the “Universidad de Concepción”, Concepción, Chile.

\section{REFERENCES}

[1] Maldague, X. (2001). "Theory and Practice of Infrared Technology for Nondestructive Testing”, $2^{a}$ Ed., John Wiley \& Sons, Inc., New York.

[2] Hari Prasad Reddy A; D.Sathis Kumar; Srisudherson; N.Parthiban; Somsubhra Ghosh; David banji. (2011). "Near infrared spectroscopy an overview". International journal of chemtech research,Vol.3, Issue 2,pp. 825-836.

[3] Seguel I. Peñaloza E. Gaete N. Montenegro A. and Torres A. 2000. Colecta y caracterización molecular de germoplasma de murta (Ugni molinae Turcz.) en Chile. Agro Sur. 28 (2):pp. 32-41.

[4] Schreckinger ME, Lotton J, Lila MA, de Mejia EG. Berries from South America: a comprehensive review on chemistry, health potential, and commercialization. Journal of Medicinal Food 2010; 13(2): pp. 223-246.

[5] Montenegro G. Nuestra flora útil. Ediciones Universidad Católica de Chile: Santiago de Chile, 2000; pp. 241-142.

[6] Scheuermann E. Seguel I. Montenegro A. Bustos R. Hormazábal E. and Quiroz A. 2008. Evolution of aroma compounds of murtilla fruits (Ugni molinae Turcz) during storage. Journal of the Science of Food and Agriculture. 88:pp. 485-492.

[7] Seguel, I.; Torralbo, L. (2004). "Murtilla: El berry nativo del sur de Chile". Revista Tierra Adentro, 57: pp. 20-25.

[8] Reyes, A., Bubnovich, V., Bustos, R., Vásquez, M., Vega, R., Scheuermann, E. (2010). "Comparative Study of Different Process Conditions of Freeze Drying of 'Murtilla' Berry”, Drying Technology, 28: 12, pp. 1416-1425.

[9] Maldague X. P. (2001) "Theory and practice of infrared technology for nondestructive testing", John Wiley \& Sons, N. Y.

[10] Parra, F., Meza, P., Pezoa, J. and Torres, S. (2011) "Thermal Characterization of a NIR Hyperspectral Camera". In Proc. of SPIE Photonic Security + Defense conference, Prague, Czech Republic, September 19-22, 2011.

[11] Osborne, B. G. 2006. Near-Infrared Spectroscopy in Food Analysis. Encyclopedia of Analytical Chemistry.

[12] H. Buning-Pfaue, "Analysis of water in food by near infrared spectroscopy", Food Chem. 82 (2003), pp. $107-115$. 